\title{
Authoritarianism as pathology of recognition: the sociological substance and actuality of the authoritarian personality
}

\author{
Benno Herzog (10) ${ }^{1 凶}$
}

The rise of the notions of authoritarianism and the authoritarian personality is directly linked to pathologies of early modernity and to social constellations that systematically produce dispositions of character that ultimately form the base of Nazi fascism. The aim of this article, thus, is to explore sociological actuality, i.e., the explanatory power and informative value of the concepts of authoritarianism and the authoritarian personality. Therefore, throughout the article, authoritarianism is framed as a social, i.e., relational approach, similar to that of recognition. However, as authoritarianism does not point towards autonomy, it can be read as a pathology of recognition. The text starts by presenting authoritarianism and authoritarian personality as introduced to the academic debate by early Critical Theory, including a description of the historical and intellectual conditions of the time. It then explores three essential elements of these concepts and how they have changed from then to now; namely, authorities, authoritarian measures, and psychological dispositions used to accept both. The sociological tools thus laid open are then used to respond to current questions about authoritarianism using the example of the impact of experts on crisis discourses. Pointing towards discursive mediation, I ask when and how the need to rely on experts fosters authoritarianism. There are basically two ways of understanding authoritarianism as still present in our society. The first is as a backward-leaning ideology of the good old times. Especially in politics, we can find a wish to overcome complex democratic decision-making procedures with strong, authoritarian leadership. The second form involves understanding authoritarianism not as a personal authority but as a swarm authority in the modern and (digital) panopticon. This pathology of recognition leads to alienated relations with others as mere anonymous providers of evaluations.

\footnotetext{
${ }^{1}$ Department of Sociology and Social Anthropology, University of Valencia, Valencia, Spain. ${ }^{凶}$ email: Benno.herzog@uv.es
} 


\section{Introduction}

he notions of authoritarianism and the authoritarian personality are "thick concepts". They not only describe specific social constellations. While the critical point arising from these notions is deeply linked to the scientific explication of fascism, both concepts at the same time serve as normative critiques: societies should not become authoritarian and should be organized such that they do not promote the creation of authoritarian personalities or at least prevent these from becoming hegemonic.

In the notorious use of the Institute of Social Research (Adorno, 1973; Horkheimer, 2005), both concepts refer to a pathology of capitalist modernity. The more psychological notion of the authoritarian personality is not meant to be a term for the individualistic critique of certain deficiencies in one's character. Moreover, the concept is closely linked to social constellations that systematically produce dispositions of character that ultimately form the base of Nazi fascism. In other words, the starting and endpoints of the critique of authoritarian personalities are not individuals but social constellations. In this sense, the notions of "character" or "personality", although inspired by psychoanalysis, have to be understood as sociological. The critique of authoritarian personalities, thus, is a social critique and a critique of authoritarian constellations, i.e., of authoritarianism.

However, in its current use, especially outside of the scientific community in public discourse, the notion of authoritarianism often seems to beg a question. It is used without considering the social conditions of authoritarianism and describes all kinds of politics from right-wing to left-wing populism and martial militarism to COVID-19 politics. In addition, we cannot overlook the fact that some of the constellations described in the first part of the last century and that gave rise to the socialpsychological character of the authoritarian personality has undergone important changes (see, Decker and Brähler, 2018; Henkelmann et al., 2020).

The aim of this article, thus, is to explore sociological actuality, i.e., the explanatory power and informative value of the concepts of authoritarianism and the authoritarian personality. Therefore, throughout the article, I frame authoritarianism as a social, i.e., relational approach, similar to that of recognition. However, as authoritarianism does not point towards autonomy, it can be read as a pathology of recognition.

I start by presenting authoritarianism and authoritarian personality as introduced to the academic debate by early Critical Theory, including a description of the historical and intellectual conditions of the time. In the second part, I explore three essential elements of these concepts and how they have changed from then to now. Namely, I examine authorities, authoritarian measures and psychological dispositions used to accept both. The sociological tools thus laid open are then used to respond to current questions about authoritarianism using the example of the impact of experts on crisis discourses. Pointing towards discursive mediation, I ask when and how the need to rely on experts fosters authoritarianism.

\section{The thesis of the authoritarian personality}

Historical background. The dedication to the authoritarian personality of early Critical Theory has to be understood in light of the crisis of Marxism, which could be said to have started roughly with World War I and culminated at the end of the first half of the century. Two crucial moments must be mentioned. First, the alignment of the European working class with militaristic nationalism. Instead of uniting forces and struggling for emancipation against international bourgeois domination, the international proletariat identified the national other as the primary enemy. World War I, or the Great War as it was then known, added a deeply worrying undertone to the question of human capacities. Instead of framing the question of what humans will be capable of doing in the future as a question full of emancipatory hope, a new form of anthropological skepticism and fear arose. The use of poison gas as a means of indiscriminate mass destruction gave the question of human capacities a frightening undertone. The history of humanity no longer had to be read as a success story of emancipation. ${ }^{1}$ From this point on, it was possible to clearly perceive the barbaric potential of modern societies.

The second event that substantially changed western Marxism was the Russian Revolution. The main impact of this event on the international working class surely was that of confirming the theory of the possibility and even inevitability of proletarian revolution. However, the aftermath of the revolution cast doubt on the emancipatory praxis of the Soviet Union. Not only the "revolutionary" elimination of tsarist and bourgeois social actors but also the persecution of revolutionary proletarian actors such as anarchists and Trotskyists started to divide the European left. The same can be said for the start of the discrediting of critical left intellectuals such as Georg Lukács and many others. Skepticism about the emancipatory character of the Soviet Union as a model for emancipation culminated with the so-called Molotov-Ribbentrop Pact, also known as the Hitler-Stalin Pact. Radical proletarians fighting fascism, often violently, across Europe thus felt that they had lost their most powerful ally.

The impossibility of reading history easily as a success story of progress and emancipation and doubts about the emancipatory potential of the working class forced two main changes to Marxist theory. These doubts shaped from this point on the direction of unorthodox Marxism, such as that institutionalized within the Institute of Social Research of Frankfurt with its critical theory, followed by an interdisciplinary group of mainly academic intellectuals. Classical Marxism, with its historical materialism, seemed incapable of understanding why the working class would act against its own objective interests. The two main approaches that critical theory introduced to classical Marxism were cultural and psychological (or psychoanalytical or sociopsychological).

The concept of culture was needed to understand that the material forces of capitalism do not act unmediated upon individuals but find themselves embedded in-and mediated through-specific cultures. In sociology, Max Weber's thesis of the influence of Protestant culture on the increase in capitalism (Weber, 2002) stands out prominently for this type of concern. In the environment of the Frankfurt School, we find, for example, Lukács (2000) with his analysis of the interplay between the economic sphere and other spheres of social life, such as the legal sphere, and Kracauer (2004) and his interest in the relations between (visual) culture, mass society and modern capitalism.

Psychological approaches were introduced to understand the irrational behaviors of humans, especially of the working class. From Freud (see especially 2002) to Fromm (e.g., 1997) and Marcuse (e.g., 1991), irrational elements of human behavior were (also) explained by the influence of pathological social constellations on the personalities of modern individuals.

The thesis. All three elements, the classical Marxist analysis of capitalist societies, theories on cultural mediation, and psychological theories, greatly influenced the study of the authoritarian personality (Adorno, 1973; Horkheimer, 2005). The theory basically states that social constellations (re-)produce a kind of 
personality - the authoritarian personality-that willingly follows authorities, power, and orders from above and is keen to exert authoritarian power over lower social groups and outsiders.

Following the authors of the study, authoritarianism is not only an economic phenomenon. Moreover, the suffix "-ism" points towards a phenomenon that crosses one clear delimited social sphere and becomes hegemonic in vast parts of society. Authoritarian constellations can be found and are reproduced in very different social spheres. In the family, for example, the patriarchal authority of the father as nourisher and head of the family is transmitted through an educational ideal of obedience. In politics, a hierarchical structure of decision-making, obedience, and rule-following are seen as more effective than mechanisms of democratic deliberation. It is the same authoritarian culture that is also experienced in the workplace. Again: a clear hierarchy, with a personally known superior, clear rules, and orders, is understood as a desirable means of organizing the sphere of production.

The material organization and social justification of important spheres of society by an authoritarian model must leave its trace in the psychological structures of individuals and in their characters or personalities. According to Adorno, the authoritarian personality not only reflects a specific character produced by a social constellation but also points towards a social pathology. Irrational moments are experienced in both the individual and the social organization. These moments could be understood with the help of psychology. While in agrarian societies, the wisdom of the elderly was considered highly valuable and therefore had authority, in modern societies this authority has slowly dissolved. The new complexity of the social order requires constant adaptation and the overthrowing of old authorities, modes of production, and socialization. Traditional values and modes of decision-making and production constantly become revolutionized. However, instead of adapting to this new situation, in a dialectical move, it seems that the more authorities are removed and therefore threatened, the more irrationally and often strongly societies hang on to old authoritarian models. The emptiness of the authoritarian superego is perceived by the authoritarian personality, but instead of formulating reflexive critique, this soproduced aggressive potential is directed towards lower social groups and outsiders.

The concept of social pathology used here has been framed differently throughout the literature (e.g., Freyenhagen, 2018; Honneth, 2008; Laitinen, 2015; Zurn, 2011). All the conceptualizations have in common that they refer to more than a specific social problem, that can be solved through concrete political, technical, or social intervention. Often, the uses refer to structural problems in society. The main use of the concept refers to a kind of second-order disorder (Zurn, 2011), i.e., a somehow false, flawed, or inverted perception about reality. And even interpretations of social pathologies as a third-order disorder-i.e., an impossibility to turn critical views into action-can be found (for a good overview see Laitinen, 2015). In this article, social pathology is understood in its most common version, as a structurally (i.e., stemming from the social order itself) flawed perception of reality with important consequences. So, when authoritarianism is seen here as a social pathology, it is in order to stress the irrational moments of insisting on an emptied form of social organization that no longer fits society. Authoritarianism can be described as a pathology because it is a lack of secondorder reflection about the changing reality.

While in specific industrial companies in the early nineteenth century, the hierarchical authorities were quite omnipresent, on a general level, the relation between capitalism and authoritarianism was not obvious. Capitalism itself is a very much impersonal form of domination. Moreover, in those where domination becomes personalized, especially in the form of the banker, the speculator, or in the figure of the Jew, it is rejected rather than embraced. Therefore, what is it about capitalism that fosters authoritarianism? There are at least three links between capitalism and authoritarianism.

First, it is precisely the abstract, negative perception of the circulation sphere that leads to a positive valuation of the sphere of production. The more the banker, the speculator, the Jew, or economic capital becomes a scapegoat and is identified as grabbing capital, the more will arise a positive identification with creative and productive industrial capital and its personalized representatives (Marx, 2012). Against the negative parasitic influence of the economic sphere stands the honorable patriarchal authority of the personal capitalist who cares not only for the business but also for "his" workers. As already said, authorities are "removed" and converted by modern capitalism from a logical and useful form of social organization into an "irrelevant" category. However, as this relation cannot be deciphered by social actors, instead of turning their aggression against capitalism and the ruling class, violence is directed towards false personifications such as the already mentioned bankers, speculators, and Jews, as well as against those even worst off within and outside society.

Second, the capitalist culture of organizations produces abstractions from the sensitive characteristics of things and beings. Group building leads to stereotyping or a "ticket mentality", as Adorno (1973) puts it. In other words, real abstraction and classification lead to the mental adoption, justification, and hierarchical ordering of this social organization. "Ticket thinking is only possible because the existence of those who give in to this type of thinking is determined to a great extent by 'tickets', by standardized, opaque and overpowering social processes that leave only very little liberty to the 'individual' for action and real individuation" (Adorno, 1973, p. 307). The ticket mentality, therefore, is not a faulty consciousness but the correct consciousness in a pathologic society. Capitalism creates a specific capitalist culture as an important precursor of the Frankfurt School, as Lukács (2000) has shown.

Third, cyclical crises are part of the capitalist mode of production (see also Harvey, 2014; Streeck, 2017). Crises do not directly lead to authoritarianism or to a desire for authoritarian measures. First, they present a certain "emergency", i.e., a situation that calls for strategies of problem-solving. However, if individuals have accepted authoritarianism as a valid resource for problem-solving, authoritarian measures regarding capitalist crises are more likely (see also Dämgen, 2020).

To avoid a common misunderstanding, it should be mentioned that the authoritarian personality as conceived by the early Frankfurt School is not akin to being a high scorer on the school's famous f-scale measuring fascist attitudes. Low scorers can have authoritarian personalities, for example, if their everyday lives are characterized by a typologized organization that leads to the ticket mentality. Therefore, it would also be erroneous to talk about one authoritarian personality, as different personalities show dispositions for authoritarian attitudes. A reified use of the concepts can be avoided by using the term syndrome in relation to authoritarian constellations (see also Adorno, 1973). The term syndrome refers to the connection of authoritarianism in different spheres and regarding different social situations. Therefore, it refers, for example, to the likelihood of negative attitudes towards one subordinated group being related to its negative attitudes towards itself.

From a sociological perspective, authority and its theses of authoritarianism and authoritarian personality have to be understood as relational. These terms express a relation between the authority and the authoritarian personality that willingly follows commands. Both, in different situations, can serve as the commanding authority or that who receives orders. At first 
glance, it could seem that we are facing here a form of recognition. Authorities have to be recognized as such by individuals to permit the following of orders. Milbradt (2020), referring to Kojève, explains that authority requires the "not executed possibility" of not following authoritarian invocation. The divine, therefore, is not an authority in the sociological sense, as there is no possibility for humans to escape divine power. Contrary to the divine or, more specifically, contrary to direct dictatorship or tyranny, the authoritarian mode of the social organization depends on emotional complicity and a will to obey (ibid.). Authority always requires a form of willing obedience that in turn depends on whatever form of legitimation is used. It is precisely this legitimation that could be understood as a basic form of recognition. The authoritarian personality recognizes the authority as a person (or institution) with specific rights for demanding obedience.

However, contrary to the mutual recognition of the tradition of left-Hegelianism, we could speak here of a pathologic form of recognition, a flawed reflection of the character of recognition. Taking Ikäheimo's (2002) definition of recognition as “a case of A taking $\mathrm{B}$ as $\mathrm{C}$ in the dimension of $\mathrm{D}$, and $\mathrm{B}$ taking $\mathrm{A}$ as a relevant judge" (p. 450), we can see the intersubjectivity inherent in this definition and therefore the social character and sociological relevance of the notion of recognition. Several aspects of this definition can be underlined:

1. Recognition is a term referring to persons, that is, to human beings with specific characteristics that can be either granted (recognized) or not granted. In this sense, when we recognize, for example, someone's right to give us orders, we recognize the human being as a person with that right. More generally, when we recognize someone as a person, we recognize her as a human being gifted with specific needs, moral capacities, and/or socially valuable traits.

2. Recognition as a notion of social interaction in two ways:

a. A person cannot be recognized by herself alone. Instead, there must be at least one person or institution that recognizes her.

b. The recognizing institution/person must be in a certain sense recognized by the other as able to provide true recognition.

It is especially this last point that, in mutual recognition, leads to a strong, autonomous, nonpathological self. It is a dialogical model based on the capacity of the individual to grant (or deny) recognition to those who recognize. This mutuality presents a democratic, empowering, and emancipatory element aiming at the autonomy of individuals.

In this sense, authoritarian dynamics could even be understood as the opposite of the mutual recognition developed by Honneth (1995), which points towards emancipation (Decker et al., 2018). In authoritarian relationships, one can precisely not develop a positive self-relation (self-confidence, self-esteem, and self-respect) but depend on an external, dominating form of recognition. The aim of recognition in left-Hegelianism is the development of an autonomous personality or a character guided by inner, reflexive forces and not by external impositions. Authoritarianism would then be a form of social pathology because it hinders the (secondorder) reflection about the full character of recognition. First, the love of the authoritarian father is as crippled as the respect of the authoritarian state towards its citizens or the esteem of the authoritarian boss towards the employees. And second, the authoritarian personality is not able to reflect on this limited character and to de-recognize the authorities, but instead is begging for the straw of pathologic recognition.

\section{The actual relevance of the thesis}

From this presentation of the main ideas of the thesis of authoritarianism, it might already be clear why the theory is sometimes considered outdated. Educational aims and family, political, and workplace organizations no longer seem to follow the ideal of hierarchical obedience. Instead, more individual responsibility, proactivity, and self-realization or the "entrepreneurial self" (Bröckling, 2015) seem to be the guiding ideals of a new form of social organization. It would be naive to think that these changes in the constellations of social organization and justification would not lead to important changes in an individual's personality. In what follows, I want to explore important aspects of authoritarianism that have changed substantially from the first half of the last century to the present.

We could roughly say that the authoritarian relation requires three elements: (a) an authority, (b) an authoritarian measure, act or requirement, and (c) a willingly obeying person. With these three different elements and the three different approaches to culture, psychology, and capitalism, we can now analyze how much authoritarian relationships have changed and what this could mean for the sociological actuality of the thesis of the authoritarian personality.

First, we must recognize that old unipersonal authorities have clearly changed or no longer exist. In the family, gender equality and a change in the educational ideal from obedience to selfdetermination have transformed inner-family interactions. Violence and the threat thereof, although still existing, is no longer seen as an adequate form of education. Dialogic pressure is imposing the need for discursive justification. In the same way, in the workplace, direct authority is often replaced with administrative management techniques. In the political realm, the trends seem less clear. Liberal democracies require collaboration, concessions, tolerance, and discursive negotiation. Foucault (2004) argues that direct paternalistic authority has been replaced with techniques of governmentality, i.e., the good government that creates and incites instead of working with top-down commands. However, there are still-again-tendencies across a large variety of national societies and of different political spectra calling for strong leadership. Here, it seems that precisely the permanent conflictivity of democracies has influenced the need for an unambiguous strong union and for leadership.

Regarding authoritarian measures, we can say that practices and ideals of punishment adopted in the family (and to some degree also in the political sphere and the workplace) have substantially changed. The shouting father and the loud boss are now seen as anachronistic. These practices no longer refer to authority but are seen as symptoms that something has grown out of the control of the former authority. In the work sphere, bonds to companies are becoming weaker. The demand to sacrifice all for the good of the company is acquiesced more due to sheer economic need and dependency, or the interiorization of external commands, than by clear authoritarian will and command on the one hand and by complicity on the part of the workers. In addition, in the political sphere, we can see that Western politics have difficulties demanding total obedience. For example, difficulties in finding the will to risk one's life for one's nation was one reason why most Western countries chose to abolish compulsory military service.

These changes in authorities and practices in all three spheres cannot be without effects on personalities. Since the last quarter of the twentieth century, it seems as if the narcissistic or hedonistic personality has been a more widespread and dominant figure than the authoritarian one. This new personality does not see in obedience an ideal to follow and is not willing to pay the price of subjection to become part of the power itself. The hedonistic or 
narcissistic personality does not want to be limited by a personal, superior authority. However, this new type of personality again depends on some form of pathological recognition: self-centered personalities depend on attention from others that constantly reaffirms their positive self-image, whether obtained from sexual partners, friends, followers, or likes on social media. This new type of personality can be interpreted as an even less autonomous individual than the authoritarian personality. Its dependence on external sources is far more diffuse and impersonal than in the case of a clear authoritarian structure.

In mutual recognition as a condition for successful selfrelation and autonomy, the self-by recognizing others-creates meaningful embeddedness in the social structure. On the contrary, in the case of mere attention or a pathological need for recognition, the other is only perceived as a mere tool. At the same time, the other, as an unrecognized other, cannot provide meaningful recognition. For the self-centered personality, the other lacks any characteristic that could give meaning to one's own recognition. Therefore, we could also speak of a form of alienation, a relation of nonrelation (Jaeggi, 2014), that leaves an empty space in the hedonistic or narcissistic personality. This alienation is a kind of estrangement in which the source of recognition, which is the very own recognition by the individual towards those who give recognition, is somehow fading away. While in true recognition, the individual itself forms part of the mutual relation of recognition, in this self-centered version, recognition becomes a one-way road from the other towards oneself. The individual is thus giving away its possibility to decide whom to recognize.

If in this constellation, the other is in some way meaningful for one's own self-relation, then this is often not due to a specific personal characteristic that is recognized by the self-centered individual but due to social status, the other had attained beforehand. Therefore, for example, a retweet of one's tweets by a celebrity is seldom valuable for the moral capacity of that celebrity but for the mere status and attention drew by this person.

Authoritarianism saved-new forms of authoritarianism. Due to these obvious changes in social reality, the concepts of authoritarianism and the authoritarian personality can no longer be used as they were used when they were developed by Adorno and collaborators in the first half of the last century. Forcing such concepts upon our current reality would mean a reification of these concepts rather than treating them as changing, sociological concepts that always depend on the specific historic context in place. So, what (if anything) can be rescued from the insights of Adorno and his collaborators? Or, to the contrary, could we perhaps say that authoritarianism and the authoritarian personality no longer play a relevant role in our societies?

One of the core ideas of authoritarianism is that of a weak individual who is willingly subject to the authority of others. The fact that today the other seldom has personal, the strong authority could cause us to perceive an end of authoritarianism. However, we could also conceive of a simple change in authority that influences the individual. Oliver Decker \& Brähler (2018, 2019) therefore speaks of "secondary authoritarianism" when referring to the impersonal authority that contemporary individuals are subjected to.

These impersonal authorities are quite diverse. Yet, it is precisely due to their diversity and even ambiguity, that they are almost omnipresent and more powerful than personal ones. The decline of the authoritarian father figure does not leave a vacuum but is replaced by other family members, peers, the mass media, and to a growing degree new and social media, as we have seen. Voluntary exposure through social networks also exposes people to all kinds of comments, including those from known peers or from the anonymous world of so-called "friends" and "followers". Individuals subject their self-relation to the recognition of an anonymous mass. Likes, friends, and followers determine levels of self-esteem and self-respect.

However, not only are sources of authority changing. In addition, the norms and values to which one must subject oneself are being blurred. In the public sphere, there are so many contradicting norms that the individual cannot follow them all. Ottomeyer (2020) mentions some of these norms and values: "empathy and egoism, honesty and outsmarting the competition, cooperation and orientation towards individual careers, 'burning for the company' and job-distance, asceticism and consumerism, thriftiness and lustfulness of wanting to possess [...] love to animals and pork cutlet, control of effects and infantilism, the pursuit of profit and the common good, impression management, and authenticity, bonding and 'freedom from bonds', fidelity in the partnership and public sexiness, manliness, and gender sensibility [...] acceleration and slowing down" (363). As is easily observed, based on these (and other incompatible) agglomerations of norms, individuals permanently find themselves in situations of insecurity, constantly vulnerable to critique. At the same time, they can always formulate critiques of others, which becomes easier with growing social distance, anonymity, and volatility in social relations and networks.

In the work sphere, constant evaluations and algorithms that measure our performance often place us in a "digital panopticon" (Angermuller, 2010). Impersonal evaluations with important material consequences for workers are omnipresent. We can evaluate our Amazon transactions, "our" Glovo riders, and Uber drivers. Hotels, restaurants, and all kinds of shops, services, and products are evaluated, recommended, and ranked by millions of willing helpers. The individual is thus exposed not to one powerful and identifiable authority but to an amorphous army to whose criteria-although not directly expressed but often hidden behind points and stars-one better subject.

We now have the conceptual tools to understand how these social conditions of constantly being under impersonal supervision present a new scenario for authoritarianism and the authoritarian personality. Despite being narcissistic, or even due to narcissism, the promise of pleasure is linked to hyperconformity. At the same time, due to contradictory norms and values, frustration, envy, shame, and aggression are constantly lurking as a threat to one's own narcissism. The current world is full of ambiguous norms. However, insecurity stemming from the ambiguity of norms under constant observation creates intolerance and an inability to bear ambiguities. Virtual arguments can break out at any moment for a crossing of any norm. Constant impersonal threat and stress, as well as a lack of clear guidelines on how to avoid risks, can be understood as a ground for contemporary, secondary authoritarianism. Furthermore, a growing number of people are excluded from the possibility of being part of the selected group of happy consumers and from experiencing even short-term satisfaction deriving from consumerism.

Although this form of behavior contains elements of (hyper) conformity (see also Castoradis, 2001), it could better be understood as a form of (secondary) authoritarianism. In sociology conformity mainly refers to the (a) implicit pressure (b) by the peers in order to fit a specific group. The impersonal evaluations mentioned here do only seldom stem from equals, but mostly from superiors and especially clients. The direction of this pressure does not aim towards fitting into the group of clients but to subordinate the evaluated under the criteria of these clients. I speak of (secondary) authoritarianism here because its main features are that of an (a) hierarchical society that gives (b) clear orders of behavior. 
Heumann and Nachtwey (2020), in their explorative research, identify a type of "regressive rebel" very similar to the authoritarian personality. What is interesting in their research is that they take a deeper look at the factors that could prevent authoritarian desolidarization. In their work, the authors identify as especially prone to regressive positions those social groups who do not experience, live or learn about cooperation and solidarity in their workplaces but whose contact with others is limited to superiors, to the marked, and to clients. This reflection relates very much to the idea of impersonal evaluation, where the evaluator is a diffuse mass or institution and not a "significant other" (Mead). There is no opportunity to recognize in any meaningful way those who recognize (or disrespect) us via an anonymous rating system. There are no dialogical forms with no negotiation of mutual recognition. Again, this type of authoritarianism seems to be a pathological form of recognition, a mere anonymous ranking. As an anonymous mass, the other is only de-facto recognized by the sheer pressure of its relevance but not due to some specific moral characteristics of those who recognize. To be full and true recognition, again, the reflection about the mutual character of this relationship is almost completely missing.

In understanding this new type of impersonal authority and narcissistic personality, we can also comprehend how authority turns into authoritarianism, i.e., how it becomes dominant. It is not only one social sphere that is under constant threat and pressure. The imperative to subject oneself to the authority of the anonymous masses and to rush towards constant selfimprovement and adaptation in a minefield of contradicting norms is present in all social spheres. For its omnipresence and early internalization, this authority can be even stronger than the external authority. Although the external authority is willingly followed, it remains an external force. According to the classical theory of authoritarianism, the willingly obeying individual takes part in authoritarian power but is not the source of it. In contrast, under secondary authoritarianism, everyone seems to be at the same time the author and the addressee of comments, likes, and discourses. By actively taking part in the valuation and ranking of others, one implicitly confirms the validity of these practices of social evaluation.

Authoritarianism as domination. Until now, we have not reflected on an important feature that seems so obvious that it can easily be forgotten. Namely, authoritarianism is a form of domination. Domination, even if having a component of voluntary submission, always involves a moment of external power or influence over the will of another. Therefore, when I ask another person for advice due to his/her expertize in a given field, this person is not part of an authoritarian dynamic as the action has its starting point in me and not in the other person. When I visit a medical doctor or I ask my tax consultant for advice, I am not only the endpoint of the action (to seek medications or modify my tax declaration) but also the one who sought a way to change my behavior in the first place.

Here, we could have other criteria for when and how authorities play a role in emancipation or act as part of an authoritarian dynamic. If the other person tries to influence my behavior unsolicited, i.e., when the other acts out of his/her own volition, then we can speak of a form of domination that can occur in authoritarian dynamics. If instead, the will has its starting and endpoints in me, then the other is not exercising domination but lending a helping hand. Or, to use Hegelian terms: when the authority is a condition for my own self-relation and life plans, then we are facing a nonpathological recognition of authority and not a pathological, authoritarian one.
The problem of domination as an essential part of authoritarian dynamics becomes more complicated if we focus on impersonal domination as present in secondary authoritarianism. Following the thesis of impersonal domination, human beings are dominated by all kinds of structural and systemic mechanisms. Not only the already mentioned likes, followers, and impersonal evaluations but also the patriarchy, capitalism, discourses, ideologies, etc. refer to different forms of domination that, although they require human beings for their reproduction, cannot be understood as personal forms of domination. This kind of domination also pushes people into subordinate positions while sustaining higher positions for others. Nonetheless, such domination does not depend mainly on the will of those in higher positions.

Again, the question of whether these impersonal moments are part of authoritarian dynamics depends on whether these impersonal structures can be considered expressions of one's own illustrated will, conditions of one's social freedom (Honneth, 2011), or institutions that hinder a positive self-relation. Institutions and structures with all of their power over the individual would then be part of freedom and not of domination if they allow the individual to understand these structures as both conditions and products of the own rational interests. In contrast, if structures and institutions hinder the development of individual rational interests, then we speak of structural domination. As is argued above, this domination is often enabled by masses of willing helpers who validate authoritarian norms and measures through everyday interactions. Therefore, we could also speak of swarm domination by an anonymous mass that imposes this secondary authoritarianism.

However, the question of whether authoritarianism truly acts against rational interests cannot easily be answered. We are here confronted with a classical problem of ideology research. Ideology, as Terry Eagleton (1991) says, is like bad breath: we only detect it in the other. In the left-Hegelian tradition ideology is always related to some false approach to reality, as a necessary inverted world consciousness (see Herzog, 2018, 2021). To state that someone has an ideological point of view seems to imply that the critic of ideology has a privileged standpoint from which to identify others who supposedly act against their own interests. If the criticized deny being trapped in ideology and affirm having real interests different than those identified by the external observer, for some orthodox critics, this would only show how deeply entrenched in a veil of ignorance the other is. In other words, once the fact that there is ideology is acknowledged, i.e., a way of thinking (and acting) contrary to the unrecognized interests of the social actor, there is no way to empirically demonstrate the truth of this statement.

The approach of authoritarianism can help us overcome this epistemological rupture of ideology research. One of the main theses about authoritarian constellations states that authoritarianism does not act against but with the interests of the dominated. Here it comes to play that ideology is not plainly false perception, but can be true and false at the same time; they can be the right perception of a wrong reality. In our case, this would mean that authoritarianism not only promises but truly provides an, at least, psychological benefit by letting the subordinate become part of the power relation and by even letting the subordinate exercise power over others, who can include outsiders, nonconformists, or even more subordinate social groups. In other words, authoritarianism relates to the interests of the dominated in a dialectical way: it acts against their legitimate interest in emancipation, autonomy, and self-determination, but at the same time, it serves some of their basic needs to be part of a power structure. Authoritarianism (traditional or 
secondary), therefore, not seduces by deceiving. Instead, it already acts in the interest of the dominated (Decker et al., 2018).

To oppose secondary authoritarianism, the very same strong personality that Adorno also mentioned with regard to (traditional) authoritarianism is needed: "Emancipated [Mündig] is who speaks for himself because he has thought for himself and not only repeats; who is not patronized. This is shown in the power to resist against pre-given opinions, and, together with that also against already existing institutions, against everything only established which justifies itself with its sheer existence" (Adorno, 1971, p. 10).

\section{Discursive mediation}

In describing the relation of the social constellation to the psychical disposition of an authoritarian personality to follow direct or indirect authoritarian orders, we have almost completely disregarded the aspect of mediation. Whether social situations lead to authoritarianism also depends on the discursive mediation of the cultural schemes available to make sense of a given situation. In other words, cultural schemes are produced not only by social constellations. At the same time, they precede social responses to the material organization of society.

The mediation of social situations becomes important when understanding authoritarianism as a pathology of recognition. As we have seen, the difference between legitimate authority and authoritarianism can be found in mutual recognition. We can understand this process of recognition as a process of discursive and symbolic communication and negotiation. When possibilities to renegotiate the position of authorities are impeded, authoritarianism is near. In this last part, I concentrate on the mediation of authoritarianism as a pathology of recognition. I do so by exploring the case of the effects of experts on crisis discourses and ask when an expert has legitimate authority and when s/he acts as a part of structural authoritarianism. With this example, we find that "old" schemes of interpretation are still present. The thread of the self-centered personality by social crisis can easily lead to new forms of old authoritarianism.

Social crises can be understood as collective perceptions of an urgent problem that requires collective attendance. At the same time, such crises present threats for the self-centered personality, as social ruptures endanger the already precarious maintenance of the (already alienated) self-relation. Here, we could consider the recent socio-financial crisis of 2008 , the climate crisis, or the recent COVID-19 crisis. In all of these cases, there is a growing social perception that "something has to be done". However, in our highly functionally differentiated society, there is often no center of power that has the capacity to bring all of this different knowledge and discourse together. There is often not even one single sphere of public discourse. Filter bubbles, echo chambers, etc. create discursive detachment from a common debate and hinder an interchange of ideas and arguments.

Therefore, the practical outcomes of debates on a crisis or discursive struggles in crisis discourses not only depend on the "unforced force of the better argument" (Habermas) but are mainly the result of power relations. Material and communicative resources established before the crisis have a continued influence on the crisis discourse. To understand crisis discourses, we, therefore, have to comprehend the power relations between the different elements of the multiple voices of the discourse. In addition, there are not only structural and material orders of discourses stemming from a pre-crisis order that might hinder a satisfactory negotiation of viewpoints, interests, and recognition. There is also the threat of the urgency and hyper-complexity of crises promoting the desire for easy, authoritarian, or populist solutions. Furthermore, the new media also form spaces of hyper- diversity in opinions and (unproven) facts. Especially since the spread of social media as a source of information, a large variety of affirmations, claims, and calls for action can be found which often even stand in direct contradiction to each other.

The social disorder requires cultural schemes to make sense of these multiple voices and to allow the social practice. The different cultural and political models available to respond to crises do not simply follow a top-down model. In different crisis discourses, we can find a different willingness of the population to give up individual freedom, submit to strong leadership and opt for national problem-solving strategies. For example, a first comparative study by Amat et al. (2020) suggested that the COVID-19 crisis has resulted in the strongest willingness to submit to authoritarian and nationalist measures. The authors compared this willingness to submit to strong leadership to what has been observed in other crises, such as the recent economic crisis and crises involving terrorist threats.

Authoritarian strategies not only stem from the government but are supported by psychological desires (of an authoritarian or narcissistic personality) and social perception. This perception can be understood as emerging from the TINA (there is no alternative) doctrine and from the creation of a specific form of social urgency from which democratic processes of deliberation must seem too lengthy and ineffective. This TINA doctrine often pairs with the idea that there is no sufficient. There can always be more action against terrorist threats, health problems, or economic risks. The lack of a standard of what can count as sufficient can perpetuate the authoritarian consequences of TINA and the will to give up ever more individual freedom in favor of struggling against certain threats.

On the other hand, following the indications of authorities is not the same as authoritarianism. The modern world is full of specialized knowledge to which we have little access, therefore requiring us to depend on the expertize of specialists. The terms used to describe these specialists usually bear different connotations. In public discourse, we can find references to "experts", "scientists" or "public intellectuals" as mainly positive connotated terms but also references to "technocrats", the "elite" or the "establishment" as increasingly negatively perceived social actors.

The terms "expert" and "technocrats" differ in that in the latter case, the necessarily partial view of the expert is implicitly criticized. Crisis discourses are discourses of complex global threats. All of these threats require a holistic understanding of the given situation. Experts usually have a very limited view. For example, a virologist has different expertize on COVID-19 than an economist or a child psychologist; feminist scholars contribute different expertize than political scientists. At the same time, experts seem to offer a stable anchor point for social perception, as we have seen throughout the COVID-19 crisis in several countries. Here, a few governmental experts explain almost on a daily basis the state of events to the population. The ritualized form of such press conferences serves-as with all rituals-as a source of stability.

The question is now whether, or rather, when and how, experts' specialized knowledge is used as part of the authoritarian constellation. This logically also includes the emancipatory question of in which social constellations highly specialized expert knowledge contributes to emancipation. Experts as persons assume a somehow hybrid position between personal and abstract authority. Although high-profile experts are wellknown personalities in a specific field, their authority does not stem from them as charismatic persons. Instead, they represent only the specific (technical) reasoning applied in their fields of expertize. Moreover, part of the success of experts as discursive actors is rooted in the fact that they do not present their advice as stemming from a specific personality but as the position of specific, technical reasoning. An expert does not call to follow 
the expert as a person but to follow impersonal, bureaucratic expert knowledge.

The measures proposed by experts are as diverse as their fields of expertize. Here, we find recommendations compatible with the narcissistic personality, such as those of economic experts wanting us to consume more to overcome an economic crisis, and classical authoritarian measures, such as those supported by a military expert recommending sending troops into a mortal battle. The legitimation of the expert as the voice of reason directly influences the will to obey. Those not following expert advice are socially positioned by the discourse as unreasonable (see also Keller, 2005). The concrete measure itself can be lamented, but the expert, as an impersonation of reason, can hardly be criticized. However, the more expert knowledge is contested and debated by other experts (as well as by laymen), the more it seems to be the expert him/herself and not abstract knowledge that calls for certain measures. In this case, experts can become objects of public critique and even of scapegoating.

For the willingness to submit to experts, we could think of expert knowledge as part of the contemporary authoritarian constellation. The classical experiment by Milgram (1974) shows how supposed academic experts were able to have others inflict harm or even kill a third person. In this famous study on obedience, framed as a scientific experiment on education, authority was followed even though most of the participants reported unease with the situation. Interviews conducted after the experiment revealed important elements of the authoritarian syndrome, including the justification of aggression towards the other due to alleged noncollaborative behavior.

From a recognitional point of view, this reflection on experts brings us to another important criterion for the differentiation of authorities from authoritarianism. Not only must there be certain mutuality in recognition. It was argued that there must also be a possibility to discursively renegotiate the relations and content of recognition. However, this would require competence among "ordinary" people to evaluate the very specific technical knowledge of experts. What is needed instead is critical access to metaknowledge, i.e., access to knowledge of the distribution and implications of expert knowledge. In times where it is very easy to access information created by self-proclaimed "experts" or those even recognized in specific filter bubbles and echo chambers such as those of climate and Holocaust deniers and creationists, it becomes increasingly important to be informed of the acknowledged experts in a specific field.

Nonetheless, from fake news to filter bubbles and from media illiteracy to the forces of information architecture (Munn, 2020), we can find several threats to this possibility of informed mediated recognition. The success of problem-solving strategies in situations of social crisis depends on the possibility of effectively orchestrating the inner logics of these discursive productions on the capacity to reinvent discourse orders, i.e., on the capacity to reform or revolutionize discursive infrastructure. With the term "discursive infrastructure", I refer to arguments, knowledge, and categories, as well as to material, institutional and practical conditions. If categories, institutions, etc. cannot be part of dynamic change, then the dangers of reification and therefore of authoritarian regression are imminent.

So, in the best of cases, specialized knowledge, represented by experts must not be understood as authoritarianism. When embedded in competent bureaucratic legitimation and metaknowledge about the relation and relevance of different expertize, then, specialized knowledge can be seen rather as a moment of emancipation. On the contrary when this bureaucratic legitimation is lacking, then, the expert is threatened to turn into the same emptied and "old" authority that was described before with regard to classical authoritarianism. These processes seem quite independent of that of secondary authoritarianism. However, secondary authoritarianism can create the basis of insecurity needed to follow experts even when they are no longer legitimized.

In situations of complex social crisis, cultural models of simple authoritarian and top-down conflict resolution strategies can sometimes be reactualized. New figures such as the expert can take personify the impersonal authority of reason. However, as the reason in complex situations exceeds by far what a sole expert or even a sole discipline can cover, expert reason can become authoritarian when not embedded in-again complex-processes of deliberation.

\section{Conclusions}

We have seen how the theory of authoritarianism and the authoritarian personality developed as a reaction to the imminent and past (but therefore no less imminent) social and political threats of the first half of the last century. The theory brought together economic, cultural, and psychological insights to understand the complex interplay between social constellations and a specific type of personality. However, social constellations have since changed in important ways. Flexibilization, acceleration, liquid modernity and so on all describe contemporary constellations in which strong and static authoritarianism is given little space.

Nevertheless, there are basically two ways of understanding authoritarianism as still present in our society. The first is as a backward-leaning ideology of the good old times. Especially in politics, we can find a wish to overcome complex democratic decision-making procedures with strong, authoritarian leadership. The second form involves understanding authoritarianism not as a personal authority but as a swarm authority in the modern and (digital) panopticon. The personality that is voluntarily subject to this secondary authoritarianism can be perfectly described as self-centered, hedonistic, or narcissistic. By mistaking attention, clicks, and likes for recognition, this personality depends on others without being able to create meaningful relationships. This pathology of recognition leads to alienated relations with others as mere anonymous providers of evaluations.

Finally, we saw how fragile secondary authoritarian constellations are. Cultural schemes of interpretation of complex problemsolving strategies as too lengthy and the psychological need for unambiguity can lead to a resurgence of old authoritarianism in new forms, for example, in the form of experts as part of a technocratic government.

In our societies, we can find a mixture of old authoritarianism, secondary authoritarianism, and old authoritarianism with new faces. Authoritarian personalities combine with self-centered personalities. Instead of being opposing forms of personality, both lack a strong sense of self. The identification of authoritarianism as a form of pathologic recognition has been able to reveal this relation to others in the form of mutual recognition and selfrelation. Only true, meaningful relations of recognition can generate nonpathological self-relations. All types of authoritarian constellations impede the creation of these meaningful relations.

Received: 21 December 2020; Accepted: 20 May 2021;

Published online: 04 June 2021

\section{Note}

1 Of course, very skeptical scenarios warning of the decline of western societies had already been raised prior to WWI. However, although these theses had a certain influence on the Marxist left, they were mostly conservative ones who saw in urban modernity an expression of social and cultural decline. 


\section{References}

Adorno ThW (1971) Kritik. Kleine Schriften zur Gesellschaft. Suhrkamp, Franfkurt/Main

Adorno ThW (coord.) (1973) Studien zum autoritären Charakter. Suhrkamp, Franfkurt/Main

Angermuller J (2010) Wissenschaft zählen. Regieren im digitalen Panopticon. Leviathan, Berliner Zeitschrift für Sozialwissenschaft 24:174-190

Amat F, Falcó-Gimeneo A, Arenas A, Muñoz J (2020) Pandemics meet democracy. Experimental evidence from the COVID-19 crisis in Spain. SocArXiv https:// doi.org/10.31235/osf.io/dkusw

Bröckling U (2015) The entrepreneurial self: fabricating a new type of subject. SAGE, London

Castoradis C (2001) The retreat from autonomy: post-modernism as generalised conformism. Democracy Nat 7(1):17-26

Decker O, Brähler E (eds) (2018) Flucht ins autoritäre. Rechtsextreme Dynamiken in der Mitte der Gesellschaft. Psychosozialverlag, Giessen

Decker O (2019) La obsolescencia del carácter autoritario y el autoritarismo secundario. Constelaciones, Revista De Teoría Crítica 10:57-73

Decker O, Schuler J, Brähler E (2018) Das autoritäre Syndrom heute. In: Decker O, Brähler E (eds) Flucht ins autoritäre. Rechtsextreme dynamiken in der Mitte der Gesellschaft. Psychosozialverlag, Giessen, pp. 1117-1155

Decker O, Yendell A, Brähler E (2018) Anerkennung und autoritäre Staatlichkeit. In: Decker O, Brähler E (eds) Flucht ins autoritäre. Rechtsextreme dynamiken in der Mitte der Gesellschaft. Psychosozialverlag, Giessen, pp. 157-177

Dämgen S (2020) Kein Subjekt. Nirgends? Autoritärer Charakter, Subjekt und Gesellschaft in der Krise. In: Henkelmann K et al. (eds) Konformistische Rebellen. Zur Aktualität des Autoritären Charakters. Verbrecher Verlag, Berlin, pp. 297-311

Eagleton T (1991) Ideology. An introduction. Verso, London

Freyenhagen F (2018) Critical Theory and Social Pathology. In: Hammer E et al. (eds) Routledge Companion to the Frankfurt School. Routledge, London, pp. $131-152$

Fromm E (1997) The fear of freedom. Routledge, London

Freud S (2002) Civilization and its discontents. Penguin, London

Foucault M (2004) Naissance de la biopolitique. Galimard, Paris

Harvey D (2014) Seventeen contradictions and the end of capitalism. Profile Books, London

Henkelmann K, Jäckel C, Stahl A, Wünsch N, Zopes B (eds) (2020) Konformistische Rebellen. Zur Aktualität des Autoritären Charakters. Verbrecher Verlag, Berlin

Herzog B (2018) Marx' critique of ideology for discours analysis: from analysis of ideologies to social critique. Critic Discourse Stud https://doi.org/10.1080/ 17405904.2018.1457549

Herzog B (2021) Ideologies as false communicative practices. J Multicult Discourse https://doi.org/10.1080/17447143.2021.1891237

Heumann M, Nachtwey O (2020) Regressive Rebellen. Konturen eines Sozialtyps des neuen Autoritarismus. In: Henkelmann $\mathrm{K}$ et al. (eds) Konformistische Rebellen. Zur Aktualität des Autoritären Charakters. Verbrecher Verlag, Berlin, pp. 385-401

Honneth A (1995) The struggle for recognition: the moral grammar of social conflicts. Polity Press, Cambridge

Honneth A (2008) Critical theory. In: Moran D (ed.) The Routledge companion to twentieth century philosophy. Routledge, London/New York, pp. 784-813

Honneth A (2011) Das Recht der Freiheit. Suhrkamp, Berlin

Horkheimer M (ed) (2005) Studien über Autorität und Familie. Forschungsberichte aus dem Institut für Sozialforschung. Dietrich zu Klampen Verlag, Lüneburg

Ikäheimo H (2002) On the genus and species of recognition. Inquiry 45:447-462

Jaeggi R (2014) Alienation. Columbia University Press, New York
Keller R (2005) Wissenssoziologische Diskursanalyse-Grundlegung eines Forschungsprogrammes. Verlag für Sozialwissenschaften, Wiesbaden

Kracauer S (2004) From Caligari to Hitler: a psychological history of the German Film. Princeton, University Press

Laitinen, A (2015) Social pathologies, reflexive pathologies, and the idea of higherorder disorders. Stud Soc Polit Thought 250 https://doi.org/10.20919/ sspt.25.2015.48

Lukács G (2000) History and class consciousness: studies in marxist dialectics. MIT Press, Cambridge

Marx K (2012) [1894] Das Kapital. Kritik der politischen Ökonomie, Vol 3. Dietz, Berlin

Marcuse H (1991) One-dimensional man: studies in ideology of advanced industrial society. Routledge, London

Milbradt B (2020) Was begreift der Begriff "Autoritarismus"? In: Henkelmann K et al. (eds) Konformistische Rebellen. Zur Aktualität des AutoritärenCharakters. Verbrecher Verlag, Berlin, pp. 53-74

Milgram S (1974) Obedience to authority: an experimental view. Harber, Michigan Munn L (2020) Angry by design: toxic communication and technical architectures. Humanit Soc Sci Commun 7:53

Ottomayer K (2020) Autoritarismus im Kapitalismus und Neoliberalismus. In: Henkelmann $\mathrm{K}$ et al. (eds) Konformistische Rebellen. Zur Aktualität des Autoritären Charakters. Verbrecher Verlag, Berlin, pp. 349-367

Streeck W (2017) Buying time. The delayed crisis of democratic capitalism. Verso, London

Weber M (2002) The Protestant ethic and the "spirit" of capitalism and other writings. Penguin, London

Zurn CF (2011) Social pathologies as second-order disorders. In: Petherbridge D (ed) Axel Honneth: Critical Essays with a Reply by Axel Honneth. Brill, Leiden, pp. 345-370

\section{Competing interests}

The author declares no competing interests.

\section{Additional information}

Correspondence and requests for materials should be addressed to B.H.

Reprints and permission information is available at http://www.nature.com/reprints

Publisher's note Springer Nature remains neutral with regard to jurisdictional claims in published maps and institutional affiliations.

(c) (i) Open Access This article is licensed under a Creative Commons Attribution 4.0 International License, which permits use, sharing, adaptation, distribution and reproduction in any medium or format, as long as you give appropriate credit to the original author(s) and the source, provide a link to the Creative Commons license, and indicate if changes were made. The images or other third party material in this article are included in the article's Creative Commons license, unless indicated otherwise in a credit line to the material. If material is not included in the article's Creative Commons license and your intended use is not permitted by statutory regulation or exceeds the permitted use, you will need to obtain permission directly from the copyright holder. To view a copy of this license, visit http://creativecommons.org/ licenses/by/4.0/

(C) The Author(s) 2021 